\title{
Bimetallic Ru-Au Catalysts: Effect of the Support
}

\author{
S. Galvagno, ${ }^{1}$ J. Schwank, and G. Parravano ${ }^{2}$ \\ University of Michigan, Department of Chemical Engineering, Ann Arbor, Michigan 48109
}

\author{
F. Garbassi
}

Istituto Guido Donegani S.p.A., Novara Research Center, Via Fauser 4, 28100 Novara, Italy

AND

\author{
A. Marzi and G. R. TAuszik \\ Montedison S.p.A., Bollate Research Center, Via San Pietro 50, 2002I Bollate, Milano, Italy
}

Received July 16, 1980; revised December 22, 1980

\begin{abstract}
$\mathrm{Ru}-\mathrm{Au}$ catalysts supported on $\mathrm{SiO}_{2}$ were characterized by using $\mathrm{H}_{2}$ and $\mathrm{O}_{2}$ chemisorption, wideangle X-ray scattering, diffuse reflectance spectroscopy, and X-ray photoelectron spectroscopy. Catalytic activity was measured for the hydrogenolysis of propane and ethane. The hydrogenolysis activity of ruthenium decreased by two orders of magnitude with addition of gold. This suggested that Ru and Au did not exist as separate particles but formed bimetallic aggregates. Chemisorption and XPS experiments showed a surface composition similar to the bulk. A comparison was made with a previously studied $\mathrm{Ru}-\mathrm{Au}$-on-MgO system, on which an enrichment of Ru on the surface of bimetallic Ru-Au clusters was discovered. It is suggested that the strength of the metal-support interaction can affect the surface composition of multimetallic supported systems.
\end{abstract}

\section{INTRODUCTION}

Previous studies on Ru-Au catalysts, supported on $\mathrm{MgO}$, led to the conclusion that ruthenium and gold form bimetallic clusters in highly dispersed systems $(I-3)$. This was a marked contrast to the behavior of the two metals in the bulk state, where ruthenium and gold are practically immiscible. An investigation of $\mathrm{CO}$ chemisorbed on these catalysts clearly showed an interaction between ruthenium and gold, modifying the characteristics of the single metals. Also, an enrichment of ruthenium at the cluster surface was discovered $(l)$. These conclusions were confirmed by a further characterization of the $\mathrm{MgO}$ supported $\mathrm{Ru}-$ Au catalysts using a variety of techniques and also by a study of the oxygen transfer

${ }^{1}$ Permanent address: Istituto Guido Donegani S.p.A.

${ }^{2}$ Deceased, April 1, 1978. between $\mathrm{CO}$ and $\mathrm{CO}_{2}(2)$. The results of the hydrogenation and hydrogenolysis of cyclopropane on the same samples indicated the formation of bimetallic $\mathrm{Ru}-\mathrm{Au}$ clusters with ruthenium enrichment on the surface (3).

The formation of bimetallic clusters in a system showing a large miscibility gap in the bulk phase is not surprising and is well documented for several systems (e.g., Ru$\mathrm{Cu}$ and $\mathrm{Os}-\mathrm{Cu},(4-9))$. More puzzling, however, is the observed enrichment of ruthenium on the surface of the $\mathrm{MgO}$ supported $\mathrm{Ru}-\mathrm{Au}$ clusters. The surface composition of bimetallic systems containing a group VIII metal and a group Ib metal has been the subject of several investigations and review articles $(10-12)$. If there is no strong chemisorptive interaction interfering, the group Ib component shows a general tendency to cover the surface of the group 
VIII metal. This phenomenon was correlated to the lower heat of sublimation and to the lower surface energy of group Ib metals (13). In the $\mathrm{Ru}-\mathrm{Au} / \mathrm{MgO}$ system, however, the opposite trend was observed, namely, a surface segregation of ruthenium $(l-3)$. Could it be that $\mathrm{Ru}-\mathrm{Au}$ represents the exception from the rule? Or are there other factors causing the deviation? It was suggested that a specific effect of the $\mathrm{MgO}$ support on the nucleation and/or growth of the metal particles could be responsible for this apparently anomalous behavior of the $\mathrm{Ru}-\mathrm{Au} / \mathrm{MgO}$ catalysts (2). To check the influence of the support material on the surface composition of $\mathrm{Ru}-\mathrm{Au}$ catalysts, a series of $\mathrm{Ru}-\mathrm{Au}$ samples was prepared on $\mathrm{SiO}_{2}$ where the interaction between the metals and the oxide material should be weaker. In a previous investigation on supported $\mathrm{Au}$ catalysts a strong interaction between $\mathrm{Au}$ and the $\mathrm{MgO}$ support was detected, while the interaction between $\mathrm{Au}$ and $\mathrm{SiO}_{2}$ was orders of magnitude weaker $(2,14,15)$. This communication reports the results obtained on a series of $\mathrm{Ru}-\mathrm{Au} / \mathrm{SiO}_{2}$ catalysts similar to those supported on MgO (1-3). The catalysts were characterized by $\mathrm{H}_{2}$ and $\mathrm{O}_{2}$ chemisorption, wideangle X-ray scattering (WAXS), diffuse reflectance spectroscopy (DRS), and X-ray photoelectron spectroscopy (XPS). The catalytic activity of the samples was tested using the hydrogenolysis of propane and ethane.

\section{METHODS}

The preparation and composition of the catalysts were similar to those of the previously studied Ru-Au/MgO samples (2).

Commercial hydrated ruthenium trichloride (Rudi Pont $\mathrm{RuCl}_{3} \cdot \mathrm{H}_{2} \mathrm{O}$, reagent grade) and "yellow gold trichloride" $\left(\mathrm{HAuCl}_{4} \cdot 3 \mathrm{H}_{2} \mathrm{O}\right.$, Carlo Erba RPE) were used as precursor compounds. The support material was silica (Davison $951 \mathrm{~N}$ ); its measured surface area was $650 \mathrm{~m}^{2} \mathrm{~g}^{-1}$. The $\mathrm{Ru} / \mathrm{SiO}_{2}, \mathrm{Au} / \mathrm{SiO}_{2}$, and $\mathrm{Ru}-\mathrm{Au} / \mathrm{SiO}_{2}$ catalysts were prepared by impregnating the support with a freshly prepared aqueous solution of the corresponding salt(s) (about $1.6 \mathrm{~cm}^{3}$ solution/g support). The salt(s) concentration in the solution was such to yield a total $(\mathrm{Ru}+\mathrm{Au})$ metal content of about 4-5 wt\% in the catalysts. The impregnated support was dried $(4 \mathrm{~h}$ at room temperature and $16 \mathrm{~h}$ at $110^{\circ} \mathrm{C}$ ) and then reduced by a purified hydrogen stream ( $2 \mathrm{~h}$ at $300^{\circ} \mathrm{C}$ and $2 \mathrm{~h}$ at $400^{\circ} \mathrm{C}$ ).

Chemisorption measurements were carried out in a conventional all-glass static system. Volumes of chemisorbed gas were calculated from the change in the gas pressure. $\mathrm{H}_{2}$ and $\mathrm{O}_{2}$ chemisorption on $\mathrm{Ru}$ and $\mathrm{Ru}-\mathrm{Au}$ samples was performed at room temperature, in the pressure range of 30 250 Torr $(1$ Torr $=133.3 \mathrm{~Pa})$. Under these experimental conditions the $\mathrm{Au} / \mathrm{SiO}_{2}$ sample did not chemisorb either $\mathrm{H}_{2}$ or $\mathrm{O}_{2}$. The $\mathrm{O}_{2}$ chemisorption on $\mathrm{Au}$ was determined at $200^{\circ} \mathrm{C}$ in the pressure range $0.2-0.7$ Torr, according to the method previously described by T. Fukushima et al. (16). The total gas uptakes were calculated by extrapolating the isotherms to zero pressure. The average particle size of the $\mathrm{Au} / \mathrm{SiO}_{2}$ and $\mathrm{Ru} / \mathrm{SiO}_{2}$ samples was calculated by the expression:

$$
d=6 \mathrm{~V} / \mathrm{S},
$$

where $d$ is the average particle size, $V$ the total metal volume, and $S$ the metal surface area.

WAXS spectra were obtained by means of a Philips X-ray powder diffractometer, equipped with a scintillation counter and a pulse height analyzer; Ni-filtered $\mathrm{Cu} K \alpha$ radiation was used. Crystallite size was calculated by Scherrer's formula after correction for the instrument contribution.

DR spectra were recorded on a PerkinElmer EPS-3T spectrometer, equipped with an integrating sphere. $\mathrm{KCl}$ was used as reference sample. Above $300 \mathrm{~nm}$, no adsorption was due to the silica support. The adsorption of the $\mathrm{Ru}-\mathrm{Au} / \mathrm{SiO}_{2}$ samples was much higher than that of the $\mathrm{Ru}-\mathrm{Au} / \mathrm{MgO}$ catalysts (2) and came close to the instru- 
mental limits. Thus, the spectra were flattened and difficult to interpret. Therefore, additional spectra were taken on $\mathrm{Ru}-$ $\mathrm{Au} / \mathrm{SiO}_{2}$ catalysts which were first finely ground and then diluted by $\mathrm{KCl}$ (the reference material). The diluted samples contained approximately $1 \%$ weight of catalyst and $99 \% \mathrm{KCl}$.

XPS measurements were performed in a PHI (Physical Electronic Industries) LEED-AES-XPS system, after inserting the powder into a pure indium foil. The pressure in the analysis chamber was maintained at $2 \times 10^{-7} \mathrm{~Pa}$ during the experiments. The $\operatorname{Mg} K \alpha$ radiation at a power of $400 \mathrm{~W}$ was used in the XPS experiments. High-resolution spectra of the following transitions were taken at a pass energy of $50 \mathrm{~V}: 01 s, \operatorname{Si} 2 p, \operatorname{Ru} 3 d_{5 / 2}, \operatorname{Ru} 3 p_{3 / 2}, \operatorname{Au} 4 f_{7 / 2}$, and $\mathrm{C} 1 s$. The Ru3 $p_{3 / 2}$ peak was chosen for the quantitative analysis, because of the overlap of the $\mathrm{C} 1 s$ contamination peak with the strongest Ru3d doublet. Atomic abundances were determined by correcting the respective intensities (assumed proportional to the peak area, after subtracting the linear background) for its photoelectric cross section, as calculated by Scofield (17).

The catalytic activity for the hydrogenolysis of propane and ethane was measured in a conventional flow system, employing a Pyrex glass reactor at atmospheric pressure, and using helium as diluent. Prepurified $\mathrm{H}_{2}$ was passed through $\mathrm{Pd}$ asbestos at $400^{\circ} \mathrm{C}$ and ultrahigh-purity $\mathrm{He}$ was passed through a Deoxo unit. Then both gases were passed through a molecular sieve trap at liquid $\mathrm{N}_{2}$ temperature. Propane and ethane, $\mathrm{CP}$ grade, were used without further purification. The analysis of products and reactants was carried out by gas chromatography (HP model 5750 with flame ionization detector). The peak areas were measured by a HP model $3380 \mathrm{~A}$ electronic integrator. The employed column was a $2-\mathrm{m}$ copper tube $(6 \mathrm{~mm}$ o.d.) filled with silica gel (100-200 mesh) which permitted the separation of $\mathrm{CH}_{4}, \mathrm{C}_{2} \mathrm{H}_{6}$, and
$\mathrm{C}_{3} \mathrm{H}_{8}$ at $80^{\circ} \mathrm{C}$. The reactor contained about 10 to $100 \mathrm{mg}$ of catalyst diluted with $0.3 \mathrm{~g}$ of the $\mathrm{SiO}_{2}$ used in the preparation of the samples. Since preliminary runs showed a decrease in activity with time, the following procedure was used to measure the initial rates. The reactant gases were passed over the catalyst for $2 \mathrm{~min}$ before sampling the products for analysis. The hydrocarbon feed and helium were then cut out and the hydrogen flow continued for $15 \mathrm{~min}$ prior to another reaction period. After 4-5 runs the catalyst was treated at $350^{\circ} \mathrm{C}$ in flowing $\mathrm{H}_{2}$ for $15 \mathrm{~min}$ and cooled at reaction temperature in $\mathrm{H}_{2}$ before taking another series of measurements. Preliminary runs performed at different flow rates showed the absence of diffusional limitations. Conversions smaller than $5 \%$ were generally employed.

\section{RESULTS}

\section{Characterization}

Quantitative analysis was performed on the reduced catalysts by atomic absorption; the results, reported in Table 1 , were used to specify the samples by symbols representing the approximate values of: $100 \times$ (number of $\mathrm{Ru}$ atoms)/(number of $\mathrm{Ru}+\mathrm{Au}$ atoms). Thus, RS048 is a sample containing about 48 at.\% $\mathrm{Ru}$ and $52 \mathrm{at} . \% \mathrm{Au}$; we recall that a similar nomenclature (e.g., R048) was used for the previously studied $\mathrm{Ru}-\mathrm{Au} / \mathrm{MgO}$ catalysts $(2,3)$.

WAXS and gas chemisorption results are reported in Table 1 . No $\mathrm{Ru}$ metal or $\mathrm{Ru}$ compounds reflections were detected by WAXS, which suggests that the Ru phase is well dispersed on the silica support, surely more than in the previously studied $\mathrm{Ru}-$ $\mathrm{Au} / \mathrm{MgO}$ samples $(1-3)$. This was confirmed also by transmission electron microscopy where particles having a diameter below $40 \AA$ were in fact observed in RS100 and RS091. Large gold crystallites were always found by WAXS, even when the Au content was only $0.61 \%$.

In the $\mathrm{Ru}$ and $\mathrm{Ru}-\mathrm{Au}$ samples, the ratio between $\mathrm{O}_{2}$ and $\mathrm{H}_{2}$ uptakes was always found close to 2 , according to the stoi- 
TABLE 1

Chemical Composition, Average Particles Size $(\bar{d})$, and Chemisorption Data for $\mathrm{Ru}-\mathrm{Au} / \mathrm{SiO}_{2}$ Catalysts

\begin{tabular}{|c|c|c|c|c|c|c|c|c|}
\hline \multirow[t]{2}{*}{ Sample } & \multirow[t]{2}{*}{ Ru (wt\%) } & \multirow[t]{2}{*}{$\mathrm{Au}(\mathrm{wt} \%)$} & \multirow{2}{*}{$\begin{array}{c}\text { WAXS, } \bar{d}^{a} \\
\text { Au }(220) \\
(\AA)\end{array}$} & \multicolumn{5}{|c|}{ Chemisorption } \\
\hline & & & & $\mathrm{H}_{2}$ Uptake $^{b}$ & $\mathrm{O}_{2}$ Uptake $^{b}$ & $\mathbf{H} / \mathbf{R u}$ & $\mathrm{O}_{2} / \mathrm{Ru}$ & $\bar{d}(\AA)^{c}$ \\
\hline RS 100 & 3.86 & - & - & 1.11 & 2.40 & 0.26 & 0.28 & 34 \\
\hline RS091 & 3.32 & 0.61 & 448 & 1.08 & 2.08 & 0.29 & 0.28 & - \\
\hline $\mathrm{RS}^{262^{d}}$ & 1.87 & 2.27 & 257 & - & - & - & - & - \\
\hline RS048 & 1.66 & 3.47 & 387 & 0.42 & 1.03 & 0.23 & 0.28 & - \\
\hline RS014 & 0.39 & 4.65 & 237 & 0.13 & 0.28 & 0.30 & 0.32 & - \\
\hline RSO00 & - & 4.69 & 276 & - & $0.061^{e}$ & - & - & 240 \\
\hline
\end{tabular}

${ }^{a}$ Ru was never detected by WAXS.

${ }^{b}$ In $\mathrm{cm}^{3}$ (STP)/g cat.

c The average particle size cannot be estimated from the chemisorption data for the bimetallic samples.

${ }^{d}$ This sample was prepared later, just to check the XPS results; chemisorption and catalytic activity tests were therefore not performed on it.

${ }^{e} \mathrm{By} \mathrm{O}_{2}$ chemisorption at $200^{\circ} \mathrm{C}$; the corresponding $0 /(2 \mathrm{Au})$ ratio is 0.046 .

chiometries $\mathrm{O} / \mathrm{Ru}=2$ and $\mathrm{H} / \mathrm{Ru}=1$. This agrees with previous literature data for small ruthenium crystallites (18). Ru and Au dispersions were calculated assuming for $\mathrm{Au}$ a stoichiometry $\mathrm{O} / \mathrm{Au}=0.5(16)$ and areas of $9.03 \AA^{2} / \mathrm{Ru}$ atom and $9.13 \AA^{2} / \mathrm{Au}$ atom $(18,2)$. The particles sizes thus obtained confirm the good dispersion of ruthenium in RS100, while Au in RS000 appears to be less dispersed, in agreement with the

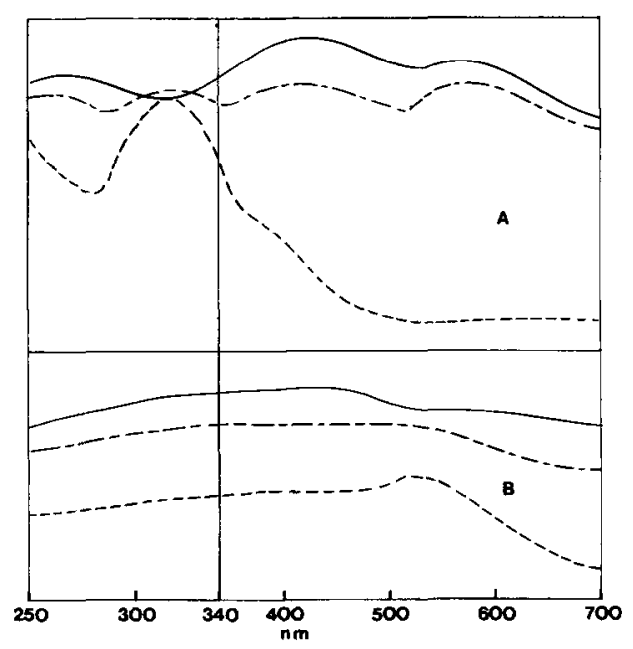

FIG. 1. Diffuse reflectance spectra (absorbance mode, arbitrary units) of samples RS100 ( -$)$, RS048 ( ---$)$, and RS000 (- - -), after dilution with $\mathrm{KCl}$. (A) Before reduction; (B) after reduction.
WAXS data. No significant effect of the $\mathrm{Ru} / \mathrm{Au}$ ratio on the metal dispersion can be pointed out.

The DR spectra of some $\mathrm{Ru}-\mathrm{Au} / \mathrm{SiO}_{2}$ samples are reported in Fig. 1 (to keep this figure simple, the spectrum of only one bimetallic sample is reported). Both before and after reduction, the spectra are significantly different than those of $\mathrm{Ru}-$ $\mathrm{Au} / \mathrm{MgO}$ (2). The spectra of the bimetallic catalysts progressively move from that of $\mathrm{Ru} / \mathrm{SiO}_{2}$ (RS 100) to that of $\mathrm{Au} \mathrm{SiO}_{2}$ (RS000). No feature suggesting an interaction between $\mathrm{Ru}$ and $\mathrm{Au}$ species could be detected. Instead, the spectra of the bimetallic $\mathrm{Ru}-\mathrm{Au} / \mathrm{MgO}$ samples were not a simple combination of those of the monometallic catalysts.

$\mathrm{Ru}$ and $\mathrm{Au}$ surface abundances measured by XPS in the reduced samples are reported in Fig. 2 and compared with those found for $\mathrm{Ru}-\mathrm{Au} / \mathrm{MgO}$ (2). They are expressed as metal/Si and metal/Mg ratios, respectively, in order to limit the effects of the other atoms (mainly $\mathrm{C}$ and $\mathrm{O}$ ) on the metal surface concentrations. Almost linear trends of surface concentration vs the bulk metal content were found for both $\mathrm{Ru}$ and $\mathrm{Au}$ in the whole composition range of the $\mathrm{Ru}-\mathrm{Au} / \mathrm{SiO}_{2}$ samples. Similar results were obtained by XPS on the corresponding un- 


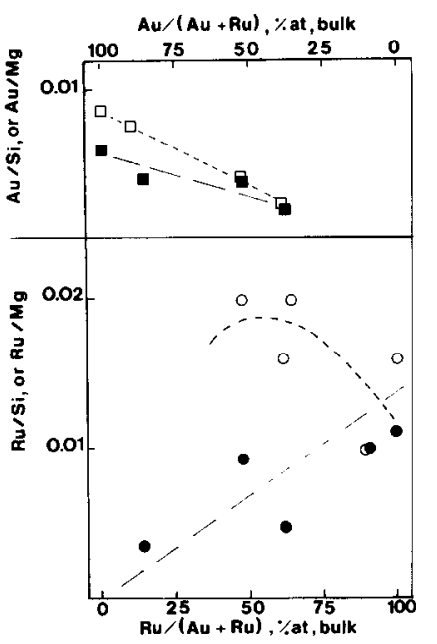

FIG. 2. $\mathrm{Ru}$ and $\mathrm{Au}$ surface abundances of $\mathrm{Ru}-$ $\mathrm{Au} / \mathrm{SiO}_{2}$ and $\mathrm{Ru}-\mathrm{Au} / \mathrm{MgO}$ catalysts (expressed as metal/Si and metal/Mg ratios, respectively) as determined by XPS: $\bullet, \mathrm{Ru} / \mathrm{Si} ; \bigcirc, \mathrm{Ru} / \mathrm{Mg} ; \mathbf{\square}, \mathrm{Au} / \mathrm{Si} ; \square$, $\mathrm{Au} / \mathrm{Mg}$.

reduced (i.e., dried) samples, as well as by Auger Electron Spectroscopy on the same reduced samples. This allows one to exclude any relevant $\mathrm{Ru}$ or $\mathrm{Au}$ surface enrichment in $\mathrm{Ru}-\mathrm{Au} / \mathrm{SiO}_{2}$, in contrast to the $\mathrm{Ru}$ segregation which appears from the trend of the $\mathrm{Ru}$ surface concentration in $\mathrm{Ru}-$ $\mathrm{Au} / \mathrm{MgO}$.

\section{Catalytic Activity}

Ethane and propane hydrogenolysis were used as test reactions. The hydrogenolysis of propane produces methane and ethane according to the following overall reactions:

$$
\begin{gathered}
\mathrm{C}_{3} \mathrm{H}_{8}+2 \mathrm{H}_{2} \rightarrow 3 \mathrm{CH}_{4}, \\
\mathrm{C}_{3} \mathrm{H}_{8}+\mathrm{H}_{2} \rightarrow \mathrm{C}_{2} \mathrm{H}_{6}+\mathrm{CH}_{4} .
\end{gathered}
$$

The rates of reaction (1) and (2) were measured at low conversion levels and calculated by the expression:

$$
N=\frac{F}{N_{\mathrm{s}}} \alpha\left[\frac{\text { molecules of } \mathrm{C}_{3} \mathrm{H}_{8}}{s \cdot \text { surface atom }}\right],
$$

where $F$ represents the feed rate of propane in molecules per second, $A_{\mathrm{s}}$ is the number of surface $\mathrm{Ru}$ atoms and $\alpha$ represents the fraction of propane that was converted to a particular product.

The hydrogenolysis of ethane produces methane according to the reaction:

$$
\mathrm{C}_{2} \mathrm{H}_{6}+\mathrm{H}_{2} \rightarrow 2 \mathrm{CH}_{4}
$$

As in the case of the propane hydrogenolysis, the rate of reaction (4) was measured at low levels of conversion, generally in the range of $0.5-5 \%$. The rate of reaction (4)

TABLE 2

Activation Energy, $E_{\mathrm{a}}$, and Catalytic Activity for the Propane Hydrogenolysis on $\mathrm{Ru}-\mathrm{Au} / \mathrm{SiO}_{2}$

\begin{tabular}{lcccc}
\hline Sample & $\begin{array}{c}\text { Temperature } \\
\text { range } \\
\left({ }^{\circ} \mathrm{C}\right)\end{array}$ & Reaction & $\begin{array}{c}E_{\mathrm{a}}{ }^{a} \\
(\mathrm{kcal} / \mathrm{mole})\end{array}$ & $\begin{array}{c}\text { Activity } \\
\left(N \times 10^{b}\right)\end{array}$ \\
\hline RS 100 & $119-157$ & 1 & 47 & 2.8 \\
RS091 & $129-162$ & 1 & 26 & 18.9 \\
RS048 & $120-184$ & 2 & 49 & 2.0 \\
& & 1 & 29 & 10.9 \\
RS014 & $149-205$ & 1 & 38 & 0.29 \\
RS000 & & 2 & 38 & 0.023 \\
\hline
\end{tabular}

${ }^{a}$ Determined at $P_{\mathrm{H}_{2}}=0.20$ atm and $P_{\text {propane }}=0.03 \mathrm{~atm}(1 \mathrm{kcal}=4.18 \mathrm{~kJ})$.

${ }^{b}$ At $160^{\circ} \mathrm{C}$; calculated according to Eq. (3). 
TABLE 3

Activation Energy, $E_{\mathrm{a}}$, and Catalytic Activity for the Ethane Hydrogenolysis-on $\mathrm{Ru}-\mathrm{Au} / \mathrm{SiO}_{2}$

\begin{tabular}{lcccc}
\hline Sample & $\begin{array}{c}\text { Temperature range } \\
\left({ }^{\circ} \mathrm{C}\right)\end{array}$ & $\begin{array}{c}E_{\mathrm{a}}{ }^{a} \\
(\mathrm{kcal} / \mathrm{mole})\end{array}$ & Activity at $160^{\circ} \mathrm{C}^{b}$ & Activity at $245^{\circ} \mathrm{C}^{c}$ \\
\hline RS 100 & $160-191$ & 29.7 & 2.68 & 7.87 \\
RS091 & $162-195$ & 29.4 & 0.92 & 2.68 \\
RS048 & $186-206$ & 28.3 & 0.36 & 0.81 \\
RS014 & $206-233$ & 24.5 & 0.14 & 0.15 \\
RS000 & $180-230$ & - & - & - \\
\hline
\end{tabular}

${ }^{a}$ Determined at $P_{\mathrm{H}_{2}}=0.2 \mathrm{~atm}$ and $P_{\text {ethane }}=0.03 \mathrm{~atm}$.

${ }^{b}\left(\mathrm{C}_{2} \mathrm{H}_{6}\right.$ molecules $) \times 10^{3} /\left(s \cdot \mathrm{Ru}_{\mathrm{s}}\right)$.

${ }^{c}\left(\mathrm{C}_{2} \mathrm{H}_{6}\right.$ molecules $) \times 10 /\left(s \cdot \mathrm{Ru}_{\mathrm{s}}\right)$.

was calculated by using Eq. (3) and expressed in molecules of ethane per second per ruthenium surface atom.

Under the experimental conditions used, $\mathrm{RS} 000\left(\mathrm{Au} / \mathrm{SiO}_{2}\right)$ was completely inactive. For the Ru-containing samples, the influence of temperature on the reaction rates was determined at a hydrocarbon partial pressure of 0.03 atm $(1 \mathrm{~atm}=$ $101,325 \mathrm{~Pa}$ ) and a hydrogen partial pressure of $0.20 \mathrm{~atm}$. The values of the apparent activation energy of the propane hydrogen-

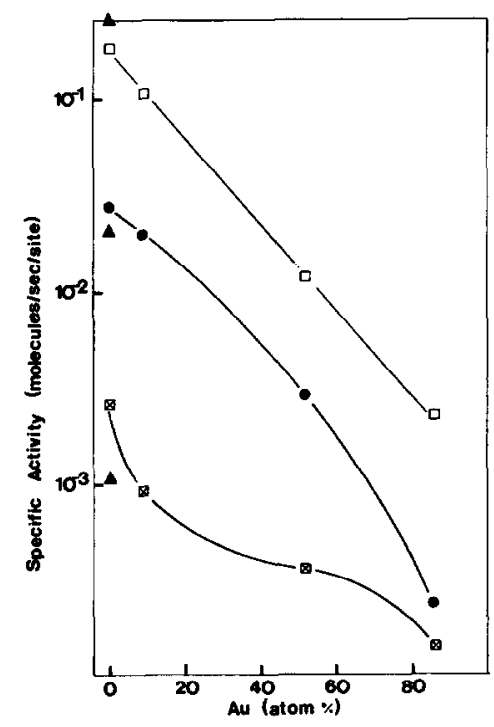

Fig. 3. Specific activity of $\mathrm{Ru}-\mathrm{Au} / \mathrm{SiO}_{2}$ catalysts for hydrogenolysis of propane via reaction (1), $\bullet$; for hydrogenolysis of propane via reaction (2), $\square$; and for hydrogenolysis of ethane, $\nabla$ at $T=160^{\circ} \mathrm{C}$. For comparison, $\mathrm{Ru} / \mathrm{SiO}_{2}$ catalyst with higher dispersion (43\%) than RS100 (A). olysis, calculated from the slope of the curve $\log N$ vs $1 / T$, are reported in Table 2 together with the values of reaction rates compared at $160^{\circ} \mathrm{C}$. The values for the activation energy of reaction (4) are reported in Table 3. Rates of reaction are given at two temperatures, namely 160 and $245^{\circ} \mathrm{C}$. This allows a comparison with the propane data (Fig. 3) and also with Sinfelt's results on $\mathrm{Ru}-\mathrm{Cu}$ (4) (Fig. 4). The extrapolation of the reaction rates to temperatures of 160 and $245^{\circ} \mathrm{C}$ was based on the Arrhenius plots. The rate per Ru surface atom of reactions (1), (2), and (4) decreased with addition of $\mathrm{Au}$, the catalytic activity of

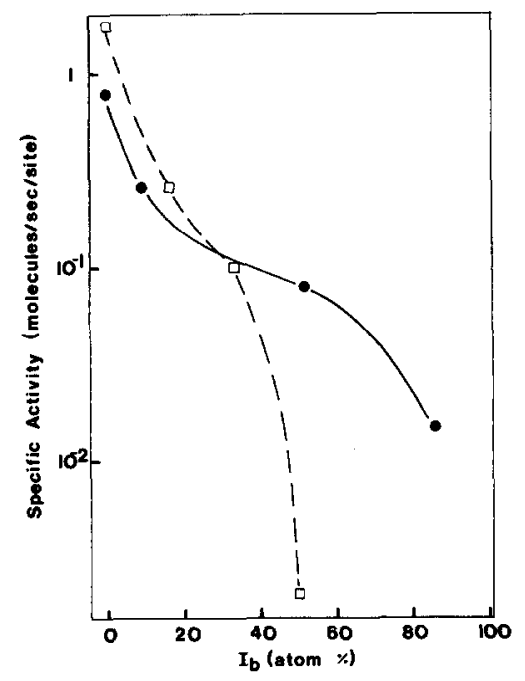

FIG. 4. Specific activity for ethane hydrogenolysis at $T=245^{\circ} \mathrm{C} . \bullet, \mathrm{Ru}-\mathrm{Au} / \mathrm{SiO}_{2}$ catalysts; $\square, \mathrm{Ru}-\mathrm{Cu} / \mathrm{SiO}_{2}$ catalysts (taken from Ref. (4)). 
RS014 (86\% Au) being more than one order of magnitude lower than that of RS100 (Ruonly sample). Furthermore, the activation energy of reactions (1) and (2) significantly decreased with addition of Au. A study of the mechanism of the hydrogenolysis of ethane and propane over the $\mathrm{Ru}-\mathrm{Au} / \mathrm{SiO}_{2}$ catalysts is reported elsewhere (19).

\section{DISCUSSION}

A comparison of the results on the $\mathrm{Ru}-$ $\mathrm{Au} / \mathrm{SiO}_{2}$ samples with the previously reported findings on $\mathrm{Ru}-\mathrm{Au} / \mathrm{MgO}$ catalysts $(l, 2)$ indicates a strong influence of the support. On the $\mathrm{SiO}_{2}$-supported bimetallic samples, the percentage of $\mathrm{Ru}$ exposed on the surface as determined by chemisorption was unaffected by the addition of gold (Table 1). In the Ru-Au/MgO system, on the other hand, the dispersion of $\mathrm{Ru}$ increased from a value of about $7 \%$ for $\mathrm{Ru}$ only (R100) to about $14 \%$ for the sample containing $90 \%$ of $\mathrm{Au}(\mathrm{R} 010)(2)$.

The nature of the support also seems to have some influence on the metal dispersion in the monometallic systems. Au supported on $\mathrm{MgO}$ had a significantly smaller average particle size $(90 \AA)$ than Au supported on $\mathrm{SiO}_{2}(240 \AA)$ under similar preparative conditions. For $\mathrm{Ru}$, the opposite trend was observed, namely a larger average $\mathrm{Ru}$ particle size on $\mathrm{MgO}$ than on $\mathrm{SiO}_{2}$. The higher dispersion of $\mathrm{Ru}$ on $\mathrm{SiO}_{2}$ can easily be explained by the much larger BET surface area of $\mathrm{SiO}_{2}\left(650 \mathrm{~m}^{2} / \mathrm{g}\right)$ in comparison to $\mathrm{MgO}\left(15 \mathrm{~m}^{2} \mathrm{~g}\right)$. This explanation does, however, not hold for the supported $\mathrm{Au}$. There, the nature of the support, and not the BET surface area, seems to be the crucial factor for the dispersion of the $\mathrm{Au}$ particles. EXAFS (2) and isotopic oxygen exchange experiments on $\mathrm{MgO}$ and $\mathrm{SiO}_{2}$ supported Au catalysts (15) have shown the presence of a strong interaction between $\mathrm{Au}$ and the $\mathrm{MgO}$ support, probably via a gold-oxygen bond. The interaction between $\mathrm{Au}$ and $\mathrm{SiO}_{2}$ was much weaker (15) and could not be detected by EXAFS (14). The stronger interaction between $\mathrm{Au}$ and the $\mathrm{MgO}$ support could account for the formation of smaller $\mathrm{Au}$ particles by preventing the sintering process. It is noteworthy that the $\mathrm{Au}$ particle size of $\mathrm{Au} / \mathrm{MgO}$ samples does not change considerably even if the catalysts, after reduction by hydrogen, are heated in oxygen for several hours at temperatures of 300 to $350^{\circ} \mathrm{C}$. This confirms the strength of the $\mathrm{Au}-\mathrm{MgO}$ interaction.

Previous results $(1-3)$ indicated an enrichment of $\mathrm{Ru}$ on the surface of the $\mathrm{Ru}-$ $\mathrm{Au} / \mathrm{MgO}$ catalysts. This Ru surface enrichment which contradicted the general tendency for group Ib metal surface enrichment, was not observed in the XPS study of the $\mathrm{Ru}-\mathrm{Au} / \mathrm{SiO}_{2}$ system. There, the metal surface composition of the bimetallic samples was similar to the bulk composition (Fig. 2). However, these XPS results do not allow one to distinguish between separate $\mathrm{Ru}$ and $\mathrm{Au}$ crystallites and bimetallic $\mathrm{Ru}-$ Au particles having a surface composition similar to the bulk composition.

Supporting evidence for the influence of the oxide material on the chemicophysical properties of the catalysts is also given by the difference among the DR spectra of $\mathrm{Ru}$ $\mathrm{Au} / \mathrm{SiO}_{2}$ and those of $\mathrm{Ru}-\mathrm{Au} / \mathrm{MgO}$. Unlike the $\mathrm{MgO}$-supported samples, $\mathrm{Ru}-\mathrm{Au} / \mathrm{SiO}_{2}$ did not show any spectral evidence for an interaction between $\mathrm{Ru}$ and $\mathrm{Au}$, both on reduced and unreduced samples. However, DR spectra alone cannot be taken as a definite proof in favor or against the existence of bimetallic $\mathrm{Ru}-\mathrm{Au}$ particles.

To get more information on the $\mathrm{Ru}-$ $\mathrm{Au} / \mathrm{SiO}_{2}$ samples and on the role of the support material, the hydrogenolysis of ethane and propane were used as test reactions. For both molecules, the rate per $\mathrm{Ru}$ surface atom decreased by addition of gold. The opposite effect, namely an increase in activity with increasing Au content, was observed in the case of $\mathrm{Ru}-\mathrm{Au} / \mathrm{MgO}$ (Fig. 5). Only catalyst R010, the $\mathrm{MgO}$ supported sample with 90 at.\% Au, showed the expected decrease in activity. In the latter case, Au was present at the catalyst sur- 


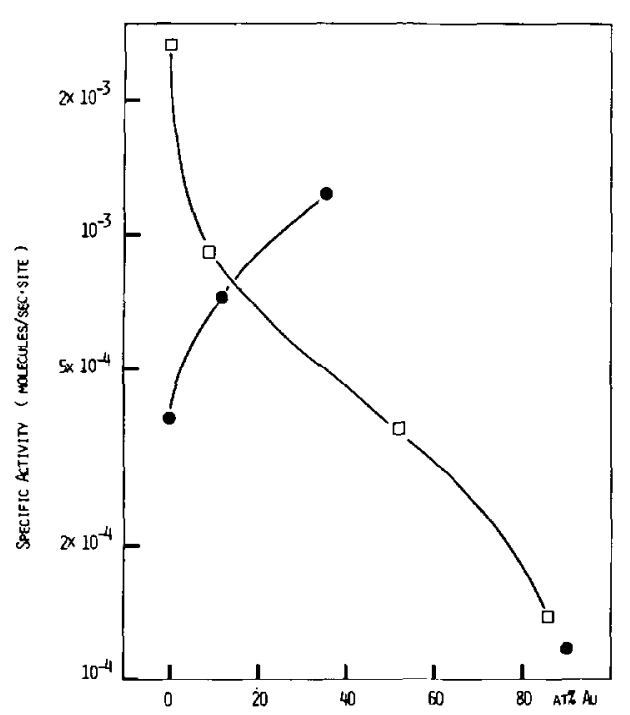

FIG. 5. Specific activity for ethane hydrogenolysis at $T=160^{\circ} \mathrm{C} . \square, \mathrm{Ru}-\mathrm{Au} / \mathrm{SiO}_{2} ; \ominus, \mathrm{Ru}-\mathrm{Au} / \mathrm{MgO}$.

face, while all the other $\mathrm{Ru}-\mathrm{Au} / \mathrm{MgO}$ catalysts had a surface made of $\mathrm{Ru}$ sites only (1). These results which are discussed in more detail elsewhere (20), are consistent with the previous findings $(I-3)$ indicating the "abnormal" behavior of the Ru$\mathrm{Au} / \mathrm{MgO}$ system.

The hydrogenolysis of hydrocarbons is generally considered a structure-sensitive reaction. Therefore, if most of the ruthenium was present as a separate monometallic phase, the decline in activity found in the $\mathrm{Ru}-\mathrm{Au} / \mathrm{SiO}_{2}$ catalysts could be caused by a change of the particle size of the active metal. But this hypothesis seems to be ruled out, in view of the almost constant dispersion of ruthenium with increasing gold content (Table 1). In this context, it is interesting to note that another $\mathrm{Ru} / \mathrm{SiO}_{2}$ sample with higher dispersion (43\%) gave an activity near to that of the RS100 sample (dispersion: $27 \%$ ) for both ethane and propane hydrogenolysis (Fig. 3). This, once again, indicates that a particle size effect is not the main cause for the decrease of the catalytic activity of ruthenium with increasing Au content.

Instead, the catalytic behavior of $\mathrm{Ru}-$ $\mathrm{Au} / \mathrm{SiO}_{2}$ recalls that reported by Sinfelt for bimetallic $\mathrm{Ru}-\mathrm{Cu}$ particles $(4,5)$. The effect of copper on the rate of ethane hydrogenolysis was explained by a $\mathrm{Cu}$ surface enrichment, in agreement with the lowering of the fraction of $\mathrm{Ru}$ atoms exposed on the catalyst surface $(4,5,7,8)$. Together with this "dilution" effect lowering the probability to find a group of active Ru atoms having the geometry required for the hydrogenolysis, also electronic interactions between $\mathrm{Cu}$ and $\mathrm{Ru}$ were considered $(4,8)$.

In our $\mathrm{Ru}-\mathrm{Au} / \mathrm{SiO}_{2}$ system, the fraction of $\mathrm{Ru}$ surface atoms is unaffected by the addition of gold and the XPS results seem to exclude any relevant gold enrichment at the catalyst surface. Therefore, it seems likely that a purely geometric "dilution" effect can have only a minor influence on the catalytic activity of $\mathrm{Ru}-\mathrm{Au} / \mathrm{SiO}_{2}$. In conclusion, it seems reasonable to assume that the decrease of the hydrogenolysis activity of ruthenium is due to an interaction between $\mathrm{Ru}$ and $\mathrm{Au}$, very likely in the form of bimetallic $\mathrm{Ru}-\mathrm{Au}$ particles.

That gold and copper affect the activity of ruthenium by somehow different mechanisms is also suggested by the comparison (Fig. 4) of the data obtained on $\mathrm{Ru}-$ $\mathrm{Cu} / \mathrm{SiO}_{2}$ (4) and on $\mathrm{Ru}-\mathrm{Au} / \mathrm{SiO}_{2}$ in the ethane hydrogenolysis (of course, this can be only a tentative comparison, since the two catalyst series were prepared and tested in two different laboratories). At low relative group Ib metal concentration, there is a striking agreement, but, at higher group $\mathrm{Ib}$ metal contents, $\mathrm{Cu}$ seems to be more effective than Au in suppressing the hydrogenolysis activity of ruthenium. This could be due to the absence of any significant surface enrichment in our $\mathrm{Ru}-\mathrm{Au} / \mathrm{SiO}_{2}$ catalysts and/or to a weaker interaction between the two metals.

The observations made on the bimetallic $\mathrm{Ru}-\mathrm{Au}$ preparations supported on $\mathrm{MgO}$ or on $\mathrm{SiO}_{2}$ can be explained by the different strength of the metal-support interaction. Gold is generally easier to reduce than ruthenium. Therefore, the first nucleation centers of metallic gold could be formed 
before the reduction of the ruthenium starts. On $\mathrm{MgO}$, these relatively small gold nucleation centers could be held in place and prevented from agglomeration and sintering by the strong interaction with the support. The subsequently formed metallic ruthenium could cover the gold nucleation centers, resulting in bimetallic clusters having a core of gold and a shell of ruthenium, in agreement with the experimental findings $(I-3)$. It is possible that under the preparative conditions used, the $\mathrm{Ru}-\mathrm{Au} / \mathrm{MgO}$ system did not reach the thermodynamic equilibrium. This hypothesis is supported by the results of a calcination treatment of the $\mathrm{Ru}-\mathrm{Au} / \mathrm{MgO}$ catalysts (2l). After heating the samples at $500^{\circ} \mathrm{C}$ in air before the reduction in $\mathrm{H}_{2}$, the "abnormal" $\mathrm{Ru}$ surface enrichment was not seen anymore. Now, a Ru/Au surface ratio near to that of the bulk was found.

On silica instead, the weaker metal-support interaction could allow a migration of the metal particles, yielding random agglomerates of $\mathrm{Au}$ and $\mathrm{Ru}$ crystallites. This could permit an electronic interaction between the ruthenium and gold crystallites, as it is suggested by the catalytic data, while the random character of the bimetallic agglomerates could account for the surface composition which resulted near to that of the bulk.

In conclusion, the results reported on the $\mathrm{Ru}-\mathrm{Au} / \mathrm{SiO}_{2}$ system and the comparison with the corresponding data on $\mathrm{Ru}-$ $\mathrm{Au} / \mathrm{MgO}$ clearly show that the support can play an important role in determining the surface composition of bimetallic catalysts. A strong interaction between one metal component and the support can cause striking deviations from the thermodynamically expected surface composition. Therefore, recently developed theories using differences in heats of sublimation, surface tensions, etc., as a basis for predicting the surface segregation of one element, might be of only limited value for bi- or multimetallic catalysts if strong metal-support interactions are present.

\section{ACKNOWLEDGMENTS}

The authors express their thanks to Montedison S. p. A. for support of this research work. J. S. and S. G. gratefully acknowledge financial support through NSF Grant ENG 7920818. Experimental assistance in the hydrogenolysis reactions was provided by Ms. Lori Golze, Ms. Kathleen Vargo, and Ms. Denise Radkowski. G. R. T., A. M., and F. G. are grateful to Dr. N. Bottazzini, Dr. M. Solari, Mr. W. Grazioli, Mr. I. Pozzi, and Mr. D. Volo for contributions to the work.

\section{REFERENCES}

I. Schwank, J., Parravano, G., and Gruber, H. L., J. Catal. 61, 19 (1980).

2. Bassi, I. W., Garbassi, F., Vlaic, G., Marzi, A., Tauszik, G. R., Cocco, G., Galvagno, S., and Parravano, G., J. Catal. 64, 405 (1980).

3. Galvagno, S., Schwank, J., and Parravano, G., J. Catal. 61, 223 (1980).

4. Sinfelt, J. H., J. Catal. 29, 308 (1973).

5. Sinfelt, J. H., Lam, L. Y., Cusumano, J. A., and Barnett, A. E., J. Catal. 42, 227 (1976).

6. Bond, G. C., and Turnham, B. D., J. Catal. 45, 128 (1976).

7. Prestridge, E. B., Via, G. H., and Sinfelt, J. H., J. Catal. 50, 115 (1977).

8. Helms, C. R., and Sinfelt, J. H., Surface Sci. 72, 229 (1978).

9. Luyten, L. J. M., V. Eck, M., V. Grondelle, J., and V. Hooff, J. H. C., J. Phys. Chem. 82, 2000 (1978).

10. Sachtler, W. M. H., Catal. Rev. Sci. Eng. 14(2), 193 (1976).

11. Ponec, V., in "Electronic Structure and Reactivity of Metal Surfaces"' (E. G. Derouane and A. A. Lucas, Eds.), Vol. 16, p. 537, NATO Advanced Study Institute Series, Series B: Physics. Plenum, New York, 1976.

12. Sinfelt, J. H., Accounts Chem. Res. 10, 15 (1977).

13. Burton, J. J., Hyman, E., and Fedak, D. G., $J$. Catal. 37, 106 (1975).

14. Cocco, G., Enzo, S., Fagherazzi, G., Schiffini, L., Bassi, I. W., Vlaic, G., Galvagno, S., and Parravano, G., J. Phys. Chem. 83(19), 2527 (1979).

15. Schwank, J., Galvagno, S., and Parravano, G., J. Catal. 63, 415 (1980).

16. Fukushima, T., Galvagno, S., and Parravano, G., J. Catal. 57, 177 (1979).

17. Scofield, J. M., Lawrence Livermore Laboratory Report UCRL-51326, 1973.

18. Taylor, K. C., J. Catal. 38, 299 (1975).

19. Galvagno, S., and Schwank, J., in preparation.

20. Schwank, J., Galvagno, S., Garbassi, F., and Tauszik, G. R., in preparation.

21. Tauszik, G. R., Garbassi, F., and Marzi, A., Gazz. Chim. It., 110, 443 (1980). 